\title{
Legal Audits: An Essential Prerequisite for Compliance Programs
}

\author{
Ronald H. Clark, JD
}

The foundation for a truly "effective" compliance plan is developed before the compliance program itself is designed and implemented. A rigorous "legal audit" or compliance review accomplishes this objective. The legal audit is a comprehensive internal investigation of the provider's operations, generally focused on one or more targeted areas. The purpose of the compliance review is to ascertain whether the provider's current practices and procedures conform with all pertinent legal requirement. Such reviews particularly focus upon detecting any potential violations of the Medicare/Medicaid Anti-Kickback Law, 42 U.S.C. § 1320a-7b(b), the Civil False Claims Act, 31 U.S.C. $\S \S 3729-33$, and pertinent regulations.

The investigative techniques cmployed in a legal audit include reviewing pertinent documents and interviewing key individuals who are either identified in the document reviews or hold essential positions (the director of billing operations, for example). Each type of health care provider has certain unique facets of its operation that should be examined (e.g., compliance with the new teaching physician rules in teaching hospitals); other issues should be examined for all providers (billing practices are a good example). A typical review might examine such elements as leases and supplier contracts, particularly those with referral sources; physician contracts and methods for documenting physician performance of contractual obligations; procedure manuals; the integrity and accuracy of the provider's billing methods; document destruction and retention policies; any audits performed internally or by outside entities such as intermediar-

From Arent Fox Kintner Plotkin \& Kahn, PLLC, Washington, DC. Mr. Clark is an attorney with Arent Fox. Address correspondence: Ronald H. Clark, JD, Arent Fox, 1050 Connecticut Avenue NW, Washington, DC. ies/carriers and governmental agencies; cost report preparation; possible "related party" transaction; and internal audit procedures.

Once the compliance review is completed, its diagnostic findings can serve multiple purposes. If the preliminary review indicates the existence of potential regulatory problems, then those areas would be examined in depth, possibly with the assistance of outside consultants, in order to ascertain if the provider actually is vulnerable and to make recommendations as to how those existing problems can be corrected. Of course protecting the attorney-client privileges is a paramount consideration. Before the compliance plan is instituted, any problems should be corrected and any necessary procedures implemented to foreclose their recurrence.

As regards designing the compliance program, the review's results should highlight any existing problems so that special attention can be devoted in the Standards of Conduct to preventing a reoccurrence. Addressing particular problem areas in the Standards also demonstrates to the government that the compliance plan is not an "off-the-shelf" document but a program custom designed for that particular provider. The compliance officer as well should be informed of the audit's results so that she may devote special attention to these potential problem areas. As part of this process it should be decided whether a written report is necessary or if an oral briefing or an "exit report" on the preliminary findings will suffice. Again, protecting privilege can be a paramount consideration at this stage.

It is also important that a determination be made, usually in conjunction with counsel, as to whether any existing problems require disclosure to the government and possible negotiation of a resolution. This frequently is a very difficult decision for the provider, who may feel that correction of a problem is sufficient action, especially given today's adverse 
enforcement environment which often seems to punish providers who are trying to act responsibly. On occasion, counsel may recommend some manner of disclosure, not necessarily under the Inspector General's "voluntary disclosure" program, in order that all regulatory problems (and potential sanctions) are climinated before the compliance plan begins opcration.

The ideal situation is to have identified and corrected all regulatory problems prior to implementation of the compliance plan. Such action demonstrates to the government that the compliance plan is a serious undertaking and that the health care provider is prepared to swallow bitter medicine if neccssary in order to cleanse its operations of any problems.
Such action can lend an important element of credibility to the compliance plan. In addition, given the extraordinary importance of "whistle blower" or qui tam lawsuits under the False Claims $\Lambda$ ct ( 31 U.S.C. $\$ 3730$ ), correcting any problems which the legal audit uncovers can foreclose substantial expense and potential legal and administrative sanctions should a potential whistle blower become aware of them.

For any number of reasons, then, instituting a demanding legal audit as a preliminary step to the design and implementation of the compliance plan can be essential to successfully designing and implementing the kind of compliance program the Sentencing Guidelines and the government expect and demand. 